\title{
CIRRHOSIS OF THE LIVER AMONG RATS RECEIVING DIETS POOR IN PROTEIN AND RICH IN FAT ${ }^{1}$
}

\author{
By GRAHAM T. WEBSTER \\ (From the Department of Medicine, Western Reserve Uniz'ersity, and the Lakeside Hospital, \\ Clec'eland)
}

(Received for publication January 13, 1942)

The importance of fat deposition in the liver as a possible contributory factor in the pathogenesis of cirrhosis was emphasized by Connor in 1939 (1). Best and Ridout (2) found that a high fat, low protein, choline-poor diet, when administered to rats, produced extensive fat deposition in the liver. It therefore seemed reasonable to administer such a diet to rats over an extended period of time in order to determine whether cirrhosis might ultimately ensue. Experiments to this end have been carried out in this laboratory (3), and recent reports of similar independent investigations have been made by György and Goldblatt (4), by Blumberg and McCollum (5), and by Lillie, Daft, and Sebrell (6). Also Chaikoff and Connor have recently reported the occurrence of cirrhosis of the liver in dogs receiving a high fat $\operatorname{diet}(7)$.

That fatty changes in the liver may be induced or aggravated in the rat by cystine feeding has been shown by Curtis and Newburgh (8), and by Lillie (9). More recently Earle and Victor (10) have reported that prolonged cystine feeding leads ultimately to cirrhosis. Cholesterol has long been known to increase the lipid content of the liver (2) and cirrhosis in the rabbit after cholesterol administration has also been observed by Chalatow (11), and more recently by Leary (12). Choline, betaine, and related compounds are agents which protect against the development of fatty livers induced by a variety of causes (2). It has also been shown by Griffith and Wade (13) that choline exerts an ameliorating effect upon the kidney necrosis which follows the administration of cystine. Because of the above findings additional groups of rats were given cystine, cholesterol, and betaine, in order to observe any modifying influence which these compounds might exert on the development of liver lesions.

1 This work was made possible by a grant in aid from the Howard M. Hanna, III, Memorial Fund.

\section{METHODS}

White rats of the Sprague Dawley strain were kept in individual cages and allowed to consume the proffered diet as desired. A basic diet, high in fat and low in protein and choline, was prepared of the following constituents per 100 grams: rice starch, 44 grams; casein, 8 grams; hydrogenated cottonseed oil, 38 grams; cod liver oil, 2 grams; salt mixture, 5 grams; whole dried brewer's yeast, 3 grams (equivalent to a daily intake of approximately 0.25 grams).2 Measurement of the quantity of diet consumed by each rat was made.

Early in this work it was discovered that cirrhotic lesions of maximum severity could be produced in mature rats weighing more than 250 grams. Hence the experiments which are reported at this time were performed on rats weighing between 250 and 450 grams and ranging in age from 4 to 9 months when they were first given the diet. There were a few exceptions which may be noted in Table I. Males seemed to be more susceptible to cirrhotic changes than females (Table I) and therefore they were used exclusively in all experiments except those employing basal diet alone. In another preliminary study, not recorded below, a number of rats were killed at varying intervals after being placed on the basal diet, in order to determine the time of onset of cirrhosis. The first evidence of fibrosis was detectable not earlier than the fourth month after the start of the diet. For this reason all rats included here were killed at the end of 150 days. Any animals dying before this time were excluded from the protocols.

\section{RESULTS}

\section{Basal diet alone}

With varying severity, the following picture was seen. The livers were large with roughened surface in hobnail form. No ascites or jaundice was observed. Those rats having the largest livers had the largest spleens. Moderate hypochromic anemia was present. The kidneys were

2 The casein was Labco brand, alcohol extracted "vitamin free," and the yeast was Strain G of Anheuser-Busch. The salt mixture was No. 185 of McCollum and Simmonds (14) with the addition of sodium fluoride 0.036 parts, manganese sulfate 0.018 parts, and potassium iodide 0.90 parts per thousand of salt mixture. 
large, pale, and coarsely granular in surface. Microscopically, the liver exhibited multilobular increases in periportal connective tissue, fat infiltration, and occasional collections of lymphocytelike cells in the periportal tissues. Bile ducts were prominent, and occasionally focal areas of necrosis were seen with lysis of cells, pyknotic nuclei, and hemorrhage. In the kidneys there were areas of cortical necrosis with hemorrhage, scarring, and focal necrotizing nephrosis. Except in the severely scarred areas, lesions in the glomeruli were minimal. The animals with relatively more severe hepatic lesions tended to have relatively less severe renal lesions and the reverse. Examination of the kidneys of a number of rats used in preliminary experiments indicated that the renal lesions were independent of age or sex. A summary of the observations made upon this group of rats is presented in Table I.

\section{Modifications of the basal diet}

Groups of 10 rats each were given the basal diet modified in various ways. With thiamin chloride and riboflavin added to the diet, 20 gamma of each per rat per day, the results were essentially the same as with basal diet alone. Addition of brewer's yeast prevented the necrosis and fibrosis when given in quantities of 2 grams per rat daily, but under these circumstances the dietary can no longer be considered to be low in protein or choline, and the proportion of fat is relatively reduced. Likewise, substitution of 2 grams of molasses ${ }^{3}$ daily for a part of the carbohydrate resulted in prevention of the necrotic and cirrhotic lesions. Variation of carbohydrate source from rice starch to glucose or sucrose, and of fat source to beef dripping or pig lard, did not alter the results.

\section{Effect of varying the percentage of protein and of fat}

The casein content of the original diet was increased to 25 per cent at the expense of the carbohydrate fraction. Only one of the 10 animals in this group showed increase in periportal connective tissue, and that was of very minor de-

3 Trixy molasses manufactured by D. B. Scully Syrup Company.

TABLE I

Rats receiving basal diet

MALES

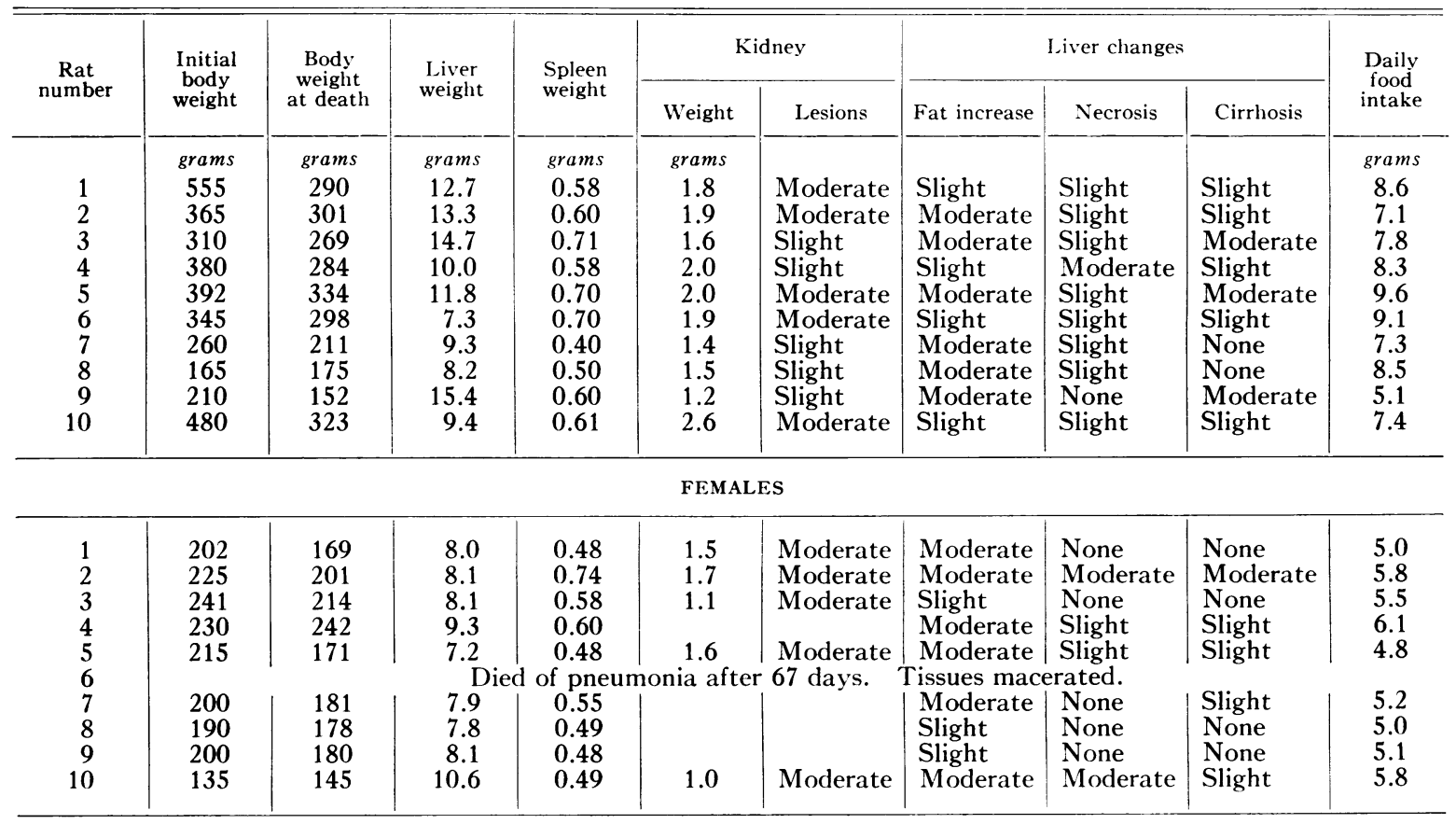



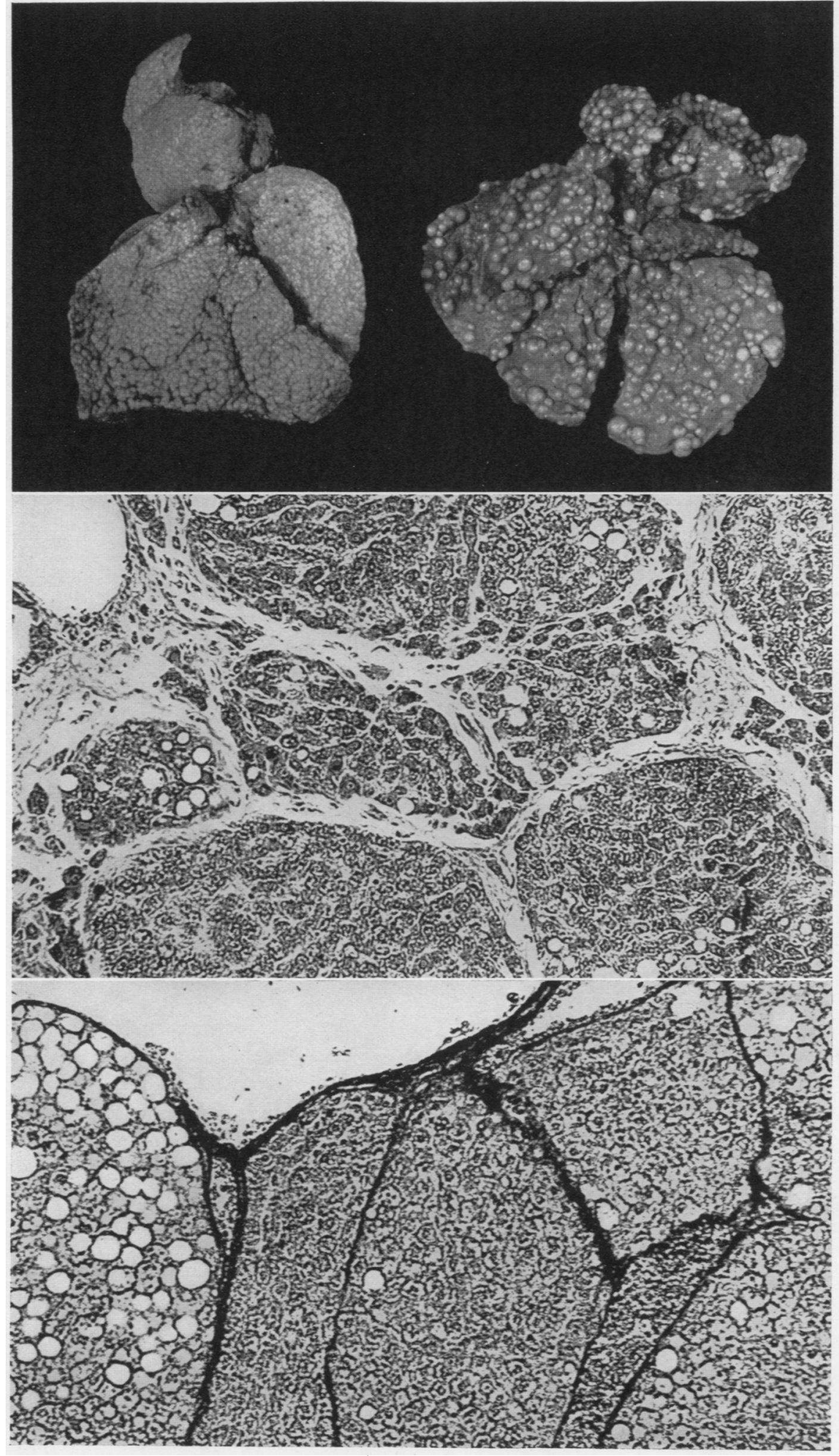

Fig. 1. Gross AsPeCt of Cirrhotic Livers

On the left, from an animal receiving the basal diet; on the right, from an animal receiving basal diet plus $10 \mathrm{mgm}$. of 1 cystine daily.

Fig. 2. Section of LIVER from Animal Receiving Basal Diet

(Hematoxylin-eosin) $X$ 140

Fig. 3. Section of Liver from Animal ReCeiving Basal Diet to Show Fat InflLtration

(Mallory's connective tissue stain) $\times 140$ 
gree. The fat content of their livers was considerably reduced, and renal disease was slight. Increase of the protein content to 25 per cent by the addition of 17 per cent gelatin to the original diet, at the expense of carbohydrate, had the same result when given to a group of 10 rats as increase in casein, except that fat infiltration was not as greatly reduced.

A decrease in fat content to 10 per cent, with increase in carbohydrate, resulted in some decrease in severity of the liver disease. Four of the 5 rats in this group showed minimal cirrhosis and one showed none. Renal lesions were also much less severe than in the original group.

\section{Effect of betaine}

The addition of betaine hydrochloride to the original diet, a choline analogue, in doses of 50 mgm. per rat daily, diminished the severity of the liver lesions, not as effectively as increased protein, but more so than diminished fat. The renal lesions were less severe than in rats receiving the basal diet. Two of the 10 animals in this group failed to survive until the end of the experiment and were excluded from the tabulation in Table II.

\section{Addition of cystine}

The addition of 1-cystine, $10 \mathrm{mgm}$. per rat daily, aggravated the fibrotic lesions of the liver, and, in this group, there was the same marked variation in severity of cirrhosis as seen in the original group. In those animals which were affected, however, there was a tendency for the increase in periportal tissue to be more extensive than in those on the basal diet. The livers of these rats were larger than those of the original group and showed a surface covered with rounded nodules. Histologically, large whorls of regenerating liver tissue were seen and among them some multinucleate giant cells. The renal lesions in this group were relatively mild except in the case of one rat which exhibited very severe scarring. Two rats had ascites but no jaundice was observed. In 2 animals, neoplasms were found. One was a primary cancer of the right lung with metastases to the mediastinal nodes. It consisted of nests and cords of small round cells of varying sizes and shapes, with frequent mitoses and moderately rich connective tissue stroma. The surrounding lung tissue was compressed but no distinct capsule could be made out. The other neoplasm arose in the pancreas and consisted of tissue similar to that described above, with many mitotic figures, multinucleate cells, and widespread metastases. The 2 rats which suffered from neoplasms had relatively less severe renal and hepatic lesions than others in this group. One animal failed to survive the 150 day experimental period.

\section{Addition of betaine and cystine}

Addition of $50 \mathrm{mgm}$. of betaine hydrochloride to the diet containing 1 -cystine prevented the very severe cirrhotic changes produced by cystine alone.

TABLE II

\begin{tabular}{|c|c|c|c|c|c|c|c|c|c|c|c|c|c|c|c|c|c|c|c|c|c|c|c|}
\hline \multirow[b]{3}{*}{ Type of diet } & \multirow[b]{3}{*}{ 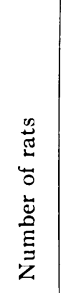 } & \multirow{3}{*}{ 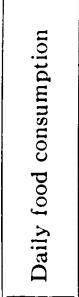 } & \multirow{3}{*}{ 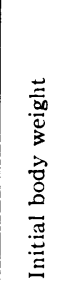 } & \multirow[b]{3}{*}{ 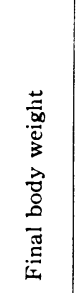 } & \multirow[b]{3}{*}{ 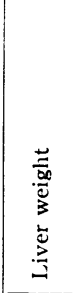 } & \multirow[b]{3}{*}{ 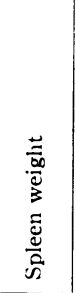 } & \multirow[b]{3}{*}{ 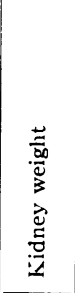 } & \multirow{2}{*}{\multicolumn{4}{|c|}{$\begin{array}{l}\text { Number with } \\
\text { kidney lesions }\end{array}$}} & \multicolumn{12}{|c|}{ Number with liver lesions } \\
\hline & & & & & & & & & & & & \multicolumn{4}{|c|}{ Increased fat } & \multicolumn{4}{|c|}{ Necrosis } & \multicolumn{4}{|c|}{ Cirrhosis } \\
\hline & & & & & & & & ¿ & 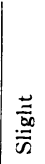 & $\begin{array}{l}\stackrel{0}{J} \\
\stackrel{0}{0} \\
\stackrel{0}{0}\end{array}$ & 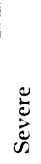 & $\stackrel{\mathscr{Z}}{\check{z}}$ & $\begin{array}{l}\stackrel{ \pm}{\sigma} \\
\stackrel{00}{\sigma}\end{array}$ & $\begin{array}{l}\stackrel{0}{\pi} \\
\stackrel{0}{0} \\
\stackrel{0}{2}\end{array}$ & 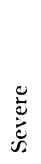 & 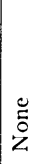 & 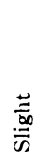 & 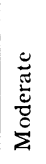 & 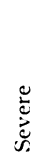 & $\begin{array}{l}0 \\
\check{z}\end{array}$ & 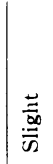 & $\frac{\stackrel{0}{\pi}}{\stackrel{0}{0}}$ & 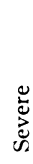 \\
\hline & & grams & grams & grams & grams & grams & grams & & & & & & & & & & & & & & & & \\
\hline Basal ....... & $10 *$ & 7.9 & 346 & 264 & 11.2 & 0.6 & 1.8 & 0 & 5 & 5 & 0 & 0 & 4 & 6 & 0 & 1 & 8 & 1 & 0 & 2 & 5 & 3 & 0 \\
\hline 25 per cent casein. & 10 & 8.2 & 368 & 346 & 11.4 & 1.3 & 2.8 & 0 & 9 & 1 & 0 & 1 & 8 & 1 & 0 & 9 & 1 & 0 & 0 & 9 & 1 & 0 & 0 \\
\hline 10 per cent fat.... & 5 & & 263 & 195 & 6.8 & 0.5 & 1.5 & 1 & 4 & 0 & 0 & 2 & 0 & 3 & 0 & 4 & 1 & 0 & 0 & 1 & 4 & 0 & 0 \\
\hline Betaine .......... & 8 & & 270 & 183 & 6.8 & 0.5 & 1.6 & 3 & 5 & 0 & 0 & 0 & 8 & 0 & 0 & 4 & 3 & 1 & 0 & 6 & 2 & 0 & 0 \\
\hline Cystine .......... & 9 & & 332 & 233 & 12.7 & 0.8 & 2.4 & 0 & 7 & 1 & 1 & 0 & 3 & 6 & 0 & 9 & 0 & 0 & 0 & 2 & 1 & 5 & 1 \\
\hline Betaine and cystine & 9 & & 334 & 217 & 11.0 & 0.8 & 1.9 & 9 & 0 & 0 & 0 & 0 & 2 & 7 & 0 & 7 & 1 & 1 & 0 & 0 & 9 & 0 & 0 \\
\hline Cholesterol ........ & 5 & & 346 & 233 & 20.2 & 1.3 & 2.7 & 0 & 0 & 3 & 2 & 0 & 0 & 0 & 5 & 5 & 0 & 0 & 0 & 0 & 0 & 2 & 3 \\
\hline
\end{tabular}

* Only male rats are included. 

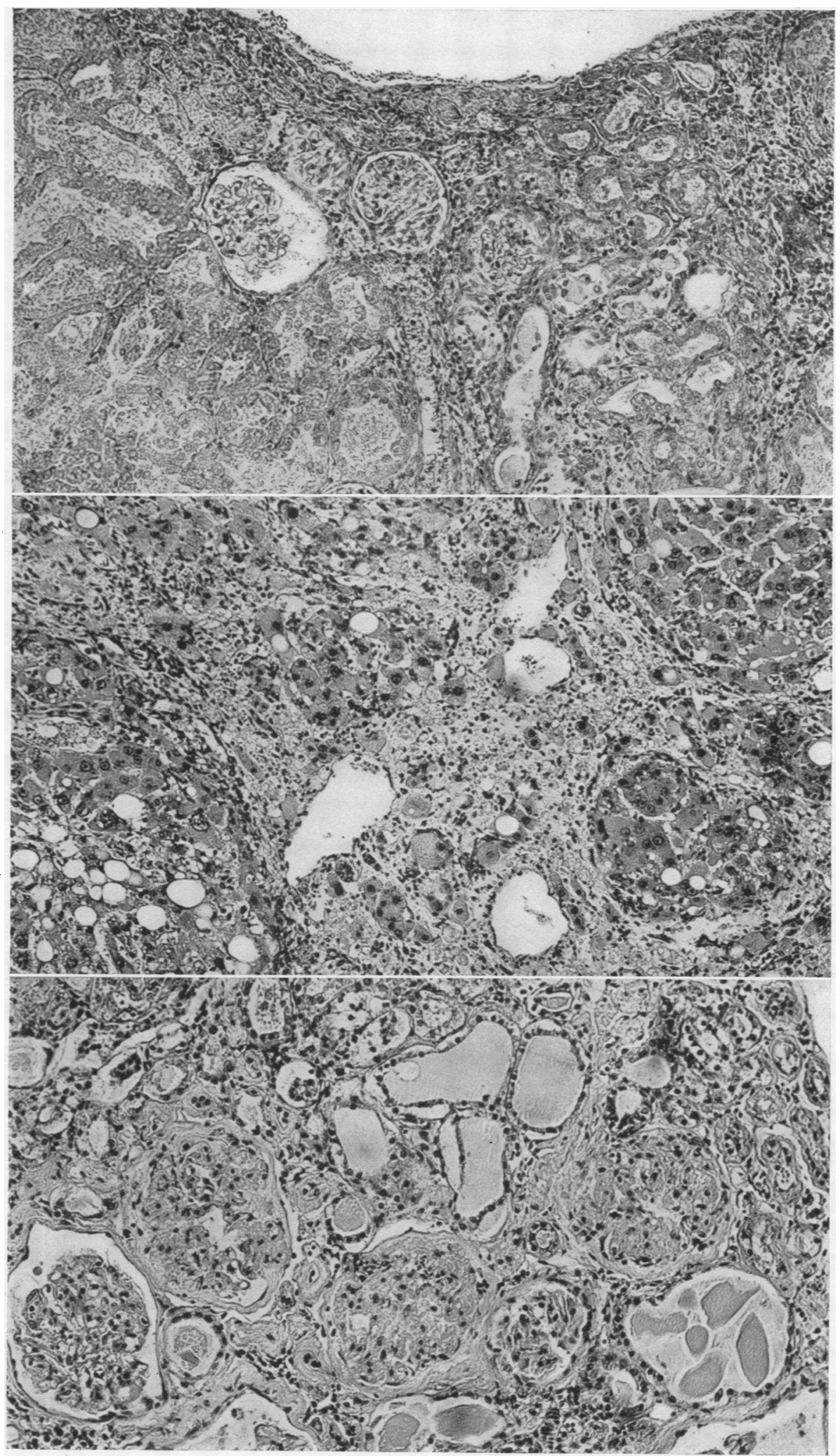

Fig. 4. Section of KIDNEY FROM RAT RECeiving Basal Diet

(Hematoxylin-eosin) $X$ 140

Fig. 5. Section of Liver FROM RAT RECEIVing Basal Diet Plus 1Cystine

(Hematoxylin-eosin) $\times$ 135

Fig. 6. Section of KidNey From ANIMAL Receiving Basal Diet Plus 1-Cystine

(Hematoxylin-eosin) $\times$ 175 
Renal lesions were absent in this group. Two animals showed nodular structures in the liver, about $1 \mathrm{~cm}$. in diameter, which appeared to be hepatomas. They were surrounded by an illdefined capsule of compressed liver tissue and were made up of multiple foci of cellular cords and clumps having no specific architectural arrangement. The clumps consisted of cells with nuclei arranged peripherally to the center at which there appeared to be a lumen. There were numerous mitotic figures and multinucleate cells. No metastases were observed. Blood supply in these areas was rich, and the cells contained very little fat as compared to surrounding liver cells. One animal of this group failed to survive.

\section{Addition of cholesterol}

Two per cent cholesterol added to the original diet caused the most severe cirrhosis and the most uniform distribution of cirrhosis among all the various groups of animals. It also caused the most severe fat infiltration of the livers although necrosis was absent. The kidneys in this group showed very severe tubular necrosis and hemorrhage.

\section{DISCLSSION}

It would seem reasonable to assume that the hepatic cirrhosis encountered in the present experiments may be attributed primarily to parenchymal damage, and that an elucidation of the pathogenesis of the lesion would necessitate an explanation of the cause of the hepatic cell dissolution. Protoplasm is undoubtedly subject to a constant state of equilibrium between protein synthesis and proteolysis. Any relative decrease in the former or increase in the latter could lead to a cellular disintegration which morphologically would consist of necrosis or atrophy. Of the various body tissues which have been studied, the highest rates of intracellular proteolysis have been found in liver and kidney (15). The predilection of the present lesions for liver and kidney is therefore correlated with the susceptibility of the cells of these organs to autoly sis. That a diet deficient in protein would promote autolysis seems quite reasonable inasmuch as the supply of protein would be insufficient to support the counterbalancing reaction of synthesis. The particular tend- ency of the liver to lose protein during fasting is brought out by the experiments of Addis, Poo, and Lew (16). The protective action of high protein diets against liver damage by chloroform (17) is further evidence of the importance of an adequate protein supply in the maintenance of liver cell integrity.

Activation of proteolysis in liver hash has been extensively studied and it has been shown that this may be brought about by a number of means (15, 18). Briefly summarized, these are: the adclition of $\mathrm{SH}$ containing compounds, of some heavy metals, chiefly arsenic and manganese, of fats, of phosphorus, of some halicles; and by anoxia. It is therefore of interest to find that cirrhosis has been aggravated in the above experiments by high cystine and fat dietaries, and has been produced in experimental animals by arsenic, manganese, phosphorus, and organic halicles (carbon tetrachloride and chloroform ) (19).

Phenylhydrazine is known to produce cirrhosis (19) and is also known to inhibit oxygen uptake by liver slices (20). With inhibition of oxygen intake, the equivalent of a state of anoxia might exist and such a state would accelerate proteolysis.

The protection offered by molasses against the liver cirrhosis cannot be adequately interpreted at this time. inasmuch as this product is a highly complex mixture of plant extractives.

With regard to the above described neoplasms. the evidence is not conclusive that they were more than isolated spontaneous occurrences in old animals that happened to be on the high cystine diets. This, however, seems improbable because 4 neoplasms occurred in 20 rats receiving cystine plus basal diet, whereas in 200 other rats of the same age, strain, and weight receiving other diets in these experiments, no neoplasms were observed. An etiological relationship between cirrhosis of the liver and hepatic neoplasms is suggested by the almost invariable coexistence of cirrhosis in the presence of primary liver tumors in man. Acceleration of the growth rate of pre-existing neoplasms in animals receiving high cystine dietaries has been reported by Voegtlin (21) and related by him to his theories of the reversibility of protein destruction in new growth and hypertrophy (22). 


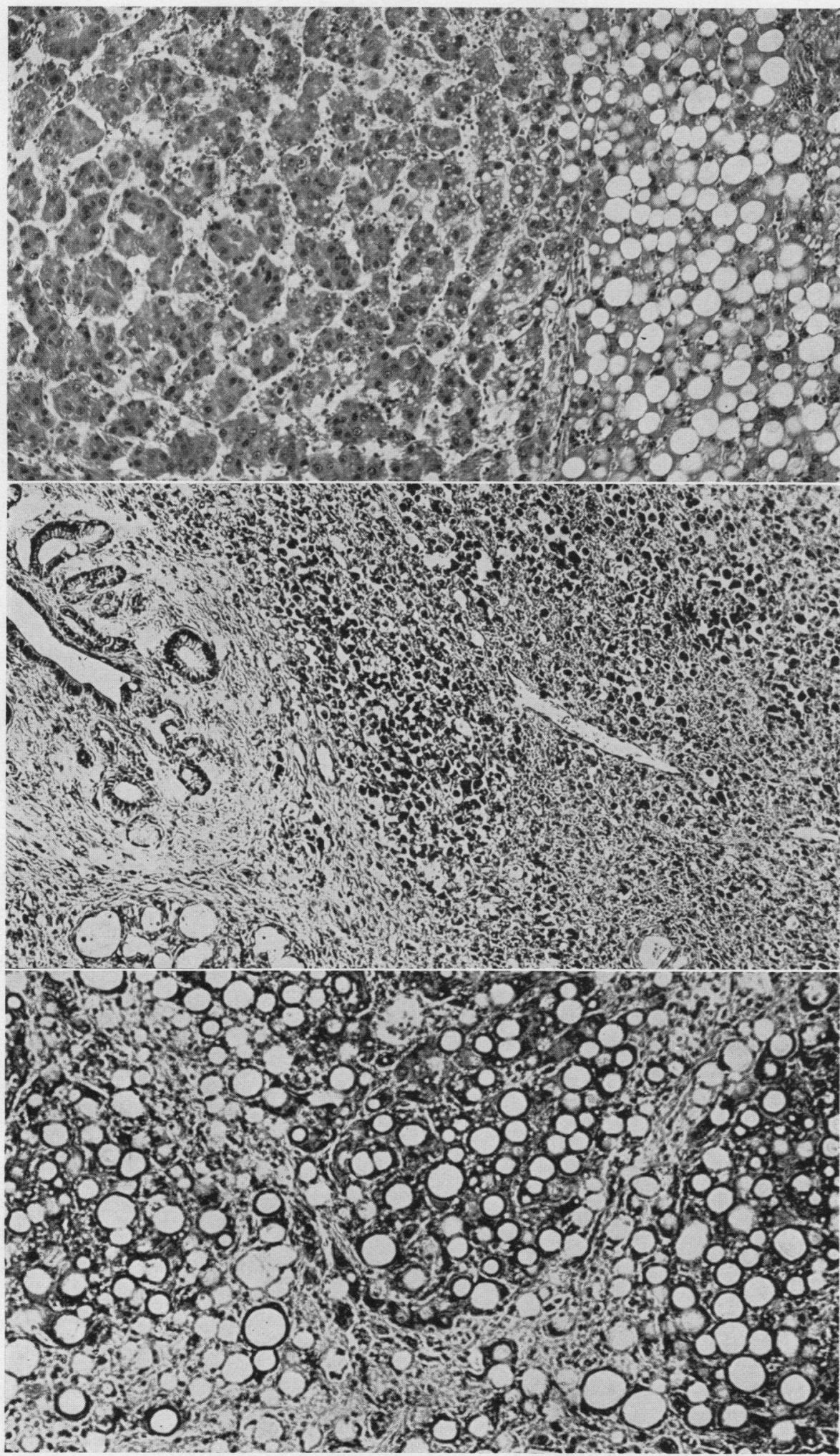

Fig. 7. Hepatoma

(Hematoxylin-eosin) $\times$ 140

Fig. 8. Section of Carcinoma of the PanCREAS INVADING T H E Wall of the Duodenum (Hematoxylin-eosin) $\times$ 135

Fig. 9. Section of LIVER FROM RAT RECEIVing Basal Diet Plus Cholesterol

(Hematoxylin-eosin) $\times$ 140 


\section{SUMMARY}

A description has been given of necrosis and cirrhosis of the liver, and of renal necrosis, fibrosis, and hemorrhage, among rats receiving diets poor in protein and choline, and rich in fat.

The hepatic lesions were prevented by an increase in the protein content of the diet and by the addition of molasses. A reduction in the fat content diminished the severity of the lesions as did the addition of betaine. Cystine and cholesterol increased the severity of the fibrotic changes. The effect of cystine was ameliorated by betaine. Thiamin and riboflavin were without influence on the disease. Yeast prevented the lesions but its efficacy could be due to the extra protein and choline which it contributed.

The renal lesions, like those of the liver, were prevented by brewer's yeast and molasses. Increased protein intake materially reduced the severity of the lesions, and thiamin and riboflavin again were without effect. A reduced proportion of fat in the diet, and the addition of betaine to the basal diet, decreased the severity of the lesions. Cystine alone had no effect on the lesions, although rats receiving cystine plus betaine showed no detectible kidney disease. Cholesterol exaggerated the lesions to a marked degree.

Neoplasms occurring in 20 per cent of the rats receiving added cystine are described.

\section{BIBLIOGRAPHY}

1. Connor, C. L., The etiology and pathogenesis of alcoholic cirrhosis of the liver. J. A. M. A., 1939, 112, 387.

2. Best, C. H., and Ridout, J. H., Choline as a dietary factor. Ann. Rev. Biochem., 1939, 8, 349.

3a. Webster, G. T., Trans. Assn. Am. Phys., 1940, 55, 139.

b. Webster, G. T., Dietary liver disease in rats. J. Clin. Invest., 1941, 20, 440.

4. György, P., and Goldblatt, H., Experimental production of dietary liver injury in rats. Proc. Soc. Exper. Biol. and Med., 1941, 46, 492.

5. Blumberg, H., and McCollum, E. V., The prevention by choline of liver cirrhosis in rats on high fat low protein diets. Science, 1941, 93, 598.

6. Lillie, R. D., Daft, F. S., and Sebrell, W. H., Jr., Cirrhosis of the liver in rats on a deficient diet and the effect of alcohol. Pub. Health Rep., 1941, $56,1255$.

7. Chaikoff, I. L., and Connor, C. L., Production of cirrhosis of liver of normal dog by high fat diets. Proc. Soc. Exper. Biol. and Med., 1940, 43, 638.

8. Curtis, A. C., and Newburgh, L. H., The toxic action of cystine on the liver of the albino rat. Arch. Int. Med., 1927, 39, 828.

9. Lillie, R. D., Histo-pathologic changes produced in rats by the addition to the diet of various amino acids. Pub. Health Rep., 1932, 47, 83.

10. Earle, D. P., Jr., and Victor, J., Cirrhosis of the liver caused by excess dietary cystine. J. Exper. Med., 1941, 73, 161.

11. Chalatow, S. S., Über experimentelle CholesterinLebercirrhose in Verbindung mit eigenen neuen Erhebungen über flïssige Kristalle des Organismus und über den Umbau der Leber. Beitr. Path. Anat., 1914, 57, 85.

12. Leary, T., The genesis of atherosclerosis. Arch. Path., 1941, 32, 507.

13. Griffith, W. H., and Wade, N. J., Relation of methionine, cystine, and choline to renal lesions occurring on low choline diets. Proc. Soc. Exper. Biol. and Med., 1939, 41, 333.

14. McCollum, E. V., and Simmonds, N., A study of the dietary essential water soluble $\mathrm{B}$ in relation to its solubility and stability towards reagents. J. Biol. Chem., 1918, 33, 55.

15. Bradley, H. C., Autolysis and atrophy. Physiol. Rev., 1922, 2, 415.

16. Addis, T., Poo, L. J., and Lew, W., Protein loss from liver during a two day fast. J. Biol. Chem., 1936, 115, 117.

17. Goldschmidt, S., Vars, H. M., and Ravdin, I. S., The influence of the foodstuffs upon susceptibility of the liver to injury by chloroform, and the probable mechanism of their action. J. Clin. Invest., 1939, 18, 277.

18. Bradley, H. C., Autolysis and atrophy. Physiol. Rev., 1938, 18, 173.

19. Moon, V. H., Compt. rend. deux Conf. Internat. de Path. Geograph., A. Oosthoek, Utrecht., 1934, page 606.

20. Bernheim, F., Bernheim, M. L. C., and Michel, H. O., The action of p-aminophenol on certain tissue oxidations. J. Pharmacol. and Exper. Therap., 1937, 61, 311.

21. Voegtlin, C., Johnson, J. M., and Thompson, J. W., Glutathione and malignant growth. Pub. Health Rep., 1936, 51, 1689.

22. Voegtlin, C., Observations concerning the chemistry of cell growth and division. Cold Spring Harbor Symp., Quant. Biol., 1934, 2, 84. 